INDUSTRIAL NURSING: ITS AIMS AND PRACTICE

By A. B. Dowson-Weisskopf, S.R.N. (Edward Arnold \& Co., London. 1944. Pp. vii +159. $5 s$.

In the rush and bustle of war new functions have frequently been fastened on to many categories of people without adequate time being given to precise definition of scope. In this country reliance is always placed upon empirical methods: we learn by experience and are suspicious of all-embracing definitions particularly in matters relating to human beings. However excellent may be the ultimate outcome of this approach, there is bound to be much muddle in the process of settling in and getting everybody to understand what has happened.

In the field of industrial hygiene, health, and welfare there has been just such a process of muddle. Orders were issued by the Ministry of Labour that medical supervision must be introduced and it was left in large measure to industry to discover what medical supervision of workers meant. Certain it is that the great majority of doctors and nurses who were thus pitchforked into industry did not know what it meant and thus different interpretations emerged. Some of these interpretations, as manifested in actual practice, were frankly reprehensible, both in the manner in which some employers defined the work's doctor's functions and in the manner in which some doctors applied their art to industry. Members of the nursing profession were appointed into industry to provide health supervision or care of workers and were in many cases grossly exploited. Regularization of the position was made possible by the efforts of the British Medical Association and the Royal College of Nursing. These bodies made valiant attempts to define the scope of medical and nursing services in industry, to lay down ethical rules, scales of salaries, and to support or organize training courses for persons proposing to enter or actually in these services.

The path to the full regularization of these services is uphill for whereas the employer has some reason to consider the doctor or nurse appointed by him as subject to his jurisdiction, the work-people have a natural tendency to suspect a service which, whilst claiming to be established in their interests, has many aspects suggestive of an interested paternalism in which the doctors and nurses have the appearance of employer's men and women. There will be much heart-burning before solution, satisfactory both to employers and workers, is found, particularly for the hosts of small concerns.

In the little volume under review, the author takes up something of a fighting position. To her the nurse in industry, considered mainly as working on her own without the direction of a medical officer, is an independent person and can exercise her authority in an enormous field; and should she be dissatisfied with any aspect of her work it is her right to beard the chairman, the managing director, or anybody else, in his den and demand satisfaction. The author goes further in saying that the nurse should discuss with the Factory Inspector the desirable changes in the factory; and even further in stating that the nurse should demand the dismissal of officials who, in her view, are having an adverse effect upon the workers' health or welfare. The state of mind of the author is illustrated by the following: 'Since industrial managements are lay bodies concerned with production and except in war-time, with marketing their goods, who may know very little about health services, it is unwise that they should entirely prescribe the limits of the nurse's work.' These limits must presumably be laid down by the nurse or by the nurse's organizations, and, says the author, it must be demonstrated to the employer by results that it pays. This is a pernicious doctrine. There is only a single criterion of the value of health and welfare service in a factory: it is that the service ministers, within its province, to the needs, physical and psychological, of the workers. That such services pay or do not pay is irrelevant and not the concern of nurses or doctors.
It is interesting that the author, in giving an example of what an annual report by the nurse should comprise, starts the report with a section headed 'Workmen's Compensation,' in which actual figures of money paid are detailed. Is it intended that corresponding to the 'Compo Doctor' there shall now be a 'Compo Nurse'? Except to report on the purely medical aspects of injury or disease, as she sees them, the nurse in industry should have nothing whatever to do with matters in which a financial transaction arises between a worker and an employer. We must confess to a certain apprehension when we hear the views of certain leaders of the nursing profession which seem to favour the development of a nurse in industry with many of the characters of business personnel. Is it too Victorian to prefer the older conception of a nurse as a person dedicated to the service of mankind-with the proviso that it shall be the business of the State to prevent exploitation-and not involved at all in the selfish scramble of commerce? It is suggested that a nurse of this kind obtains the co-operative and understanding response from employers and professional managers, coupled with respectful deference and even homage, which are never obtained by the business-woman type.

We would recommend the perusal of this little book rather as an index of topics calling for study by the industrial nurse than as a reliable text-book for practice. For the latter the nurse in the factory will have to look elsewhere.

M. W. G.

\section{ABSENCE FROM WORK: PREVENTION OF} FATIGUE

Industrial Health Research Board Pamphlet No. 2

(H.M. Stationery Office. 1944. Pp. 20. 3d.)

It is not an easy matter to describe the results of scientific research in simple language, or in terms that can be understood by 10 million workers in industry. Investigation into the varied problems of absenteeism and of fatigue involve technical details and descriptions which have been presented from time to time in reports from the Board. It has undoubtedly taken courage, therefore, for a research body to depart from precedent by simplifying language and to enter the field of education. But results fully justify the decision. This pamphlet, even more so than its predecessor on ventilation and lighting, is a brilliant example of what can and must be done to make the findings of scientific research understandable to everybody. For $3 d$. we have a gold-mine of information. Attractive illustrations add to its interest. But its motif is dead serious and the facts it presents are an indictment of our industrial machine. During this war absentee rates of 6-8 per cent. for men, and 10-15 per cent. for women are generally found. While some reasons for this may be outside the control of the individual worker, the lead in prevention must be taken by the group of people most directly concerned-the men and women on the job of production, and this includes the highest management. "Weekly hours of work should not exceed 60 for men and 55 for women ... for heavy manual workers and women with home duties these hours are still too long a week-end break is important . . . weekly hours should wherever possible be spaced over a five-day week in severe muscular work a break of 5 or 10 minutes every hour is better than a single break of 15 minutes in the middle of a spell . . . it is often possible to adjust the machine, the seating, or arrangements of work so as to avoid excessive strain and waste of energy.' These are strong words; and they hit hard at many employers.

Although the pamphlet already sells by the thousand, it must sell by the tens of thousands and more. Those of us who work in industry-doctors, nurses, welfare workers, managers, and shop stewards-must act as selling agents. For example it would be good to see it on railway station bookstalls. Facts are given to us in straight downright talk; the remedy is suggested; it is for the people of this country to decide what will be done. 